\title{
Análise qualitativa dos sentimentos e conhecimentos acerca da gestação e do HIV em gestantes soropositivas e soronegativas
}

\section{Qualitative analysis of feelings and knowledge's about pregnancy and HIV in seropositive and seronegative pregnant women}

\author{
Cristiane Pimentel Hernandes ${ }^{1}\left(\mathbb{D}\right.$, Rafaela Kuczynski da Rocha ${ }^{2},\left(\mathbb{D}\right.$, Andrey Hausmann $^{2}\left(\mathbb{D}\right.$, Jhenifer Bibiana Appelt ${ }^{2}(\mathbb{D})$, Cassiano \\ de Mattos Marques² $^{2}$ (D)
}

1. Docente do Curso de Medicina da Universidade de Santa Cruz do Sul (Unisc), Santa Cruz do Sul, RS, Brasil. 2. Discente do Curso de Medicina da Universidade de Santa Cruz do Sul (Unisc), Santa Cruz do Sul, RS, Brasil.

\begin{abstract}
Resumo
Introdução: com a ocorrência da chamada feminização do HIV, tornou-se comum mulheres descobrirem a infecção pelo vírus do HIV no pré-natal em virtude do rastreamento. Entender como tal grupo de gestantes lida com o processo de gestação e de maternidade em relação a grupos de outros fatores de risco é pertinente. Objetivo: realizar uma análise epidemiológica, da percepção e expectativa das gestantes portadoras do HIV em relação ao filho, de questões relacionadas ao autocuidado antes e durante a gestação, comparando com gestantes que apresentam gestação de alto risco, mas soronegativas. Método: foi realizado um estudo qualitativo que entrevistou aleatoriamente 22 gestantes, 10 soropositivas e 12 soronegativas e questionou sobre suas perspectivas em relação à gestação; além da avalição do perfil epidemiológico dessa população. Resultados: as gestantes apresentam um perfil epidemiológico similar ao âmbito nacional. Ambos os grupos apresentam sentimentos comuns em relação ao processo gestacional, parto, e conhecimento sobre transmissão vertical. Entretanto, gestantes soropositivas passam por algumas dificuldades, tanto emocionais, quanto sociais, e preocupações diferentes de gestantes soronegativas. 0 fato de estar presente a infecção pelo vírus do HIV, durante a gestação, trouxe uma série de temores, como a da transmissão vertical, malformações, julgamento social de estar perpetuando a doença, além da impossibilidade de amamentar. Em contraponto, foi possível perceber que todos esses conflitos que, em um primeiro momento, são desesperadores, podem se tornar motivos de superação, de maior cuidado com a saúde e maior planejamento, se as mães infectadas pelo vírus do HIV tiverem o acompanhamento correto. Conclusão: é essencial a existência de uma equipe multidisciplinar preparada para lidar com os conflitos das gestantes, além de educá-las quanto às formas de transmissão vertical. Em especial no grupo soropositivo, o apoio psicológico quanto ao medo de transmissão vertical e ao processo de confrontar o fato de não poder amamentar faz necessário, pois isso estabelece uma confiança mútua, tanto da paciente em relação a equipe de saúde, quanto da equipe em relação à paciente, algo que é central para a saúde da mãe e do bebê.
\end{abstract}

Palavras-chave: Gestação. HIV/Aids. Diagnóstico. Atenção psicossocial.

\begin{abstract}
Introduction: the occurrence of so-called feminization of HIV has become common for women to discover HIV infection in prenatal care due to screening. It is important to understand the way a group of pregnant women handles the process of pregnancy and maternity in relation to groups of other risk factors. Objective: the purpose of this study is to verify epidemiology, perception and expectation of pregnant women with HIV in relation to their child, to self-care issues before and during gestation in comparison to seronegative pregnant women who present other high-risk factors. Methodology: a random qualitative study interviewed 22 pregnant women, 10 seropositive women and 12 seronegative women. The women were questioned about their perspectives regarding to pregnancy and then this population was evaluated. Results: it was concluded that pregnant women in the region of the study had an epidemiological profile similar to the national level. Both groups showed common feelings about the gestational process, childbirth, and knowledge about mother-to-child transmission. However, seropositive pregnant women had to face some emotional and social difficulties and had different concerns compared to seronegative pregnant women. Pregnant women infected by HIV are worried about mother-to-child transmission, malformations, social judgment of perpetuating the disease and the impossibility of breastfeeding. However, it was possible to notice that all these conflicts, which at first are desperate, become reasons for overcoming if mothers infected with the HIV virus have the correct follow-up. Conclusion: it's fundamental to have a multidisciplinary team prepared to handle with the difficulties of pregnant women and to educate them about mother-to-child transmission. In seropositive group, psychological support to face the fear of mother-to-child transmission and the process of confronting the fact that they can't breastfeed is essential. It is crucial to trust in the health care team for the health of the mother and the baby.
\end{abstract}

Key words: Gestation; HIV/Aids. Diagnosis. Psychosocial attention

\section{INTRODUÇÃO}

Quando descoberta, a infecção pelo vírus da imunodeficiência humana (HIV) era considerada uma doença pertencente a determinado grupo de pessoas denominado grupo de risco (composto especialmente por homossexuais e usuários de drogas injetáveis). Hoje, essa não é mais a realidade, fato demonstrado pela heterossexualização da epidemia do HIV e 
pelo aumento do número de mulheres infectadas, ocorrência chamada de feminização do HIV ${ }^{1,2,3}$. Por exemplo, no Brasil em 2007 , o número de casos notificados do sexo feminino foi 2811 , número que, em 2017, considerando apenas o período de janeiro a fevereiro, quase duplicou, totalizando 4491 casos $^{4}$. No período de 2000 até junho de 2017, foram notificadas 108.134 gestantes infectadas com HIV4. Com isso, novas medidas preventivas tiveram que ser pensadas em termos de saúde pública, entre essas, a solicitação da sorologia anti-HIV durante o pré-natal. É, durante o período gestacional, que grande parcela de mulheres é diagnosticada com o HIV, tornando esse momento importante para a prevenção da transmissão vertical do vírus, melhora dos níveis de assistência maternoinfantil e aconselhamento em relação às infecções sexualmente transmissíveis e HIV/Aids ${ }^{1,5}$.

Sabe-se que o grande problema do HIV na gestação é o fato de haver a possibilidade de transmissão do vírus para o feto ou recém-nascido. A transmissão vertical é responsável pelo contágio por HIV na maioria das crianças infectadas até 13 anos. Sabe-se que, no Brasil, é a via de transmissão responsável por quase totalidade dos casos $(93,1 \%)^{4}$, sendo essa feita por disseminação placentária, exposição do feto ao sangue ou secreções maternas na passagem pelo canal de parto e, também, por meio do aleitamento materno ${ }^{2,6,7}$. A testagem para o HIV deve ocorrer, portanto, no primeiro trimestre de gestação, para tratamento precoce e prevenção da transmissão intraútero (responsável por cerca de $35 \%$ das transmissões), no terceiro trimestre até antes do trabalho de parto, a para utilização de antirretroviral intraparto, prevenindo a transmissão durante o parto (responsável por cerca de $65 \%$ das transmissões) ${ }^{2,7,8}$.

Para as mulheres soropositivas, que ainda não iniciaram o tratamento com antirretrovirais e que desejam ser mães, ou as que descobrem seu diagnóstico durante o pré-natal, as diretrizes do Ministério da Saúde preconizam tratamento antirretroviral com Tenofovir, Lamivudina e Raltegravir como primeira escolha. Para as gestantes infectadas pelo HIV já em uso de terapia antirretroviral prévia ao diagnóstico da gestação com carga viral indetectável, recomenda-se manter o mesmo esquema utilizado, desde que ele não contenha dolutegravir'. O tipo de parto é determinado não somente por indicação obstétrica, mas também pela carga viral da gestante, realizandose parto cesáreo quando a carga viral for considerada alta ou desconhecida. Além disso, durante o trabalho de parto, devese realizar profilaxia com zidovudina (AZT) a partir do início do trabalho de parto até o clampeamento do cordão umbilical ${ }^{9}$. Também é preconizado o tratamento do recém-nascido com AZT, associado, ou não, à Nevirapina, nas quatro primeiras semanas de vida?.

A gestação de alto risco é definida quando alguma comorbidade (biológica ou sociodemográfica) ocorre e as avaliações e o uso de tecnologias mais complexas tornam-se necessários10. A gestação, por si só, já representa um grande processo psicológico baseado nas expectativas das mães quanto aos seus bebês, sua saúde e como será a interação materno-fetal. Quando a gestante passa por um processo além do esperado, são comuns os sentimentos como angústia, medo e solidão gerarem um desgaste maior que o esperado no processo gestacional10. No caso de gestantes soropositivas, a maioria descobre-se portadora do HIV durante o pré-natal e, por isso, passam a conviver com uma situação dolorosa, aterrorizante, tendo que lidar com sentimentos de remorso e tristeza ${ }^{1,5,7,11}$.

Este estudo objetiva realizar um perfil epidemiológico de gestantes de alto risco portadoras, ou não, do HIV, tendo em vista a importância do conhecimento desse tipo de análise para a compreensão do contexto social e a identificação de indicadores de risco, bem como a avaliação de algumas ações de prevenção e a promoção da saúde durante o período gravídico. Além disso, busca analisar a percepção e a expectativa da gestante portadora do HIV em relação ao filho, de questões relacionadas ao autocuidado antes e durante a gestação, comparando com gestantes que apresentam alto risco, mas ausentes de soropositividade, evidenciando quais fatores diferem nesses dois grupos, tentando relacionar possíveis fatores presentes no grupo soropositivo que impactem, diretamente, na qualidade de vida da gestante, do feto e, futuramente, do recém-nascido.

\section{MÉTODOS}

Estudo transversal qualitativo de casos coletivos realizado com 22 gestantes, sendo 10 gestantes HIV positivas que frequentavam o serviço referência para tratamento de HIV/Aids em um município do interior do Rio Grande do Sul e 12 gestantes HIV negativas com comorbidades que frequentavam o serviço de referência para a gestação de alto risco no mesmo município. Para coleta de dados, as gestantes foram abordadas de forma aleatória conforme a procura pelo serviço de atendimento, no período de 6 meses. Os critérios de seleção foram ser gestante maior de 18 anos, querer participar da entrevista, apresentar HIV/Aids ou alguma outra patologia que caracterizasse gestação de alto risco, todas independentemente da idade gestacional. Antes da coleta de dados, as gestantes foram orientadas quanto aos propósitos do estudo, esclarecendo que tal projeto não apresentaria algum risco para elas. Todas assinaram o Termo de Consentimento Livre e Esclarecido. A pesquisa foi aprovada em 8/1/2015 pelo Comitê de Ética e Pesquisa (CAAE: 34025714.0.0000.5343), e os dados foram coletados no período de 10/3/2016 a 10/9/2016.

A primeira parte do questionário consistia em caracterizar a amostra a partir de dados demográficos e epidemiológicos por meio de questões fechadas, cujas respostas foram preenchidas manualmente pelo pesquisador. Foram considerados nesse questionário as variáveis: idade; raça; escolaridade; profissão; estado civil; número de parceiros sexuais (na vida e no último ano); uso de preservativos; uso de medicamentos; uso de drogas ilícitas; número de filhos; número de gestações anteriores; número de abortos; número de natimortos; idade gestacional; número de consultas pré-natais até o momento; se soropositiva, o tempo de soropositividade; e se fazia uso de terapia antirretroviral.

A segunda parte consistia em um questionário específico com 
perguntas abertas para a avaliação da percepção da saúde e das expectativas das gestantes em relação à gestação e ao recémnascido. Essa parte da entrevista foi gravada com um gravador de áudio em uma sala de consultório isolada para posterior íntegra transcrição e compilação das respostas. As perguntas foram "Você estava planejando ser mãe?"; "Se você tivesse que definir sua gravidez em uma palavra, qual seria?"; "O que você espera do futuro do bebê?"; "Você sente medo da gestação e/ou do trabalho de parto? Por quê?"; "Você se considera saudável? Por quê?"; "Quais são as formas de contaminação do vírus HIV da mãe para o bebê?"; "Você já realizou o teste antiHIV no seu atual pré-natal?", se negativo, "Quais são as suas expectativas em relação à gestação e ao bebê?", se afirmativo, "Suas expectativas mudaram após o resultado, seja ele positivo ou negativo?".

Os dados epidemiológicos coletados foram processados no programa Microsoft Excel, versão 2010, com base em estatística descritiva, organizando os dados em tabelas para melhor interpretação e discussão. Os dados qualitativos foram agrupados conforme a ideia central, ou seja, por meio da interpretação das respostas transcritas, e o grupo à qual pertencia a gestante (BARDIN, 2011)12. As entrevistas foram então analisadas e divididas em 5 temas conforme literatura pertinente ao tema: A) Planejamento materno e expectativas em relação ao futuro do bebê; B) Temores relacionados à gestação e ao trabalho de parto; C) Percepção de saúde; D) Conhecimento sobre transmissão vertical; E) Teste anti-HIV e mudanças de perspectivas.

\section{RESULTADOS E DISCUSSÃO}

A amostra total foi de 22 mulheres, sendo dessas 10 soropositivas. Em relação ao perfil sociodemográfico, de acordo com a Tabela 1, a média de idade do grupo de gestantes soropositivas foi de 30 anos (máxima de 42 anos e, mínima, de 20 anos); no grupo soronegativo, a idade média foi de 27 anos (máxima de 36 anos e mínima de 18 anos), dados semelhantes aos obtidos em outras análises sociodemográficas em que a maioria das gestantes HIV positivas estava na faixa etária de 2130 anos $^{2,5}$, e com dados brasileiros em que essa faixa representa em torno de $51,4 \%$ em $2017^{4}$. No que diz respeito à raça, $40 \%$ das gestantes HIV positivas se autodeclararam branca, ao passo que, nas HIV negativas, 66,67\% afirmaram ser brancas e uma gestante desse grupo não quis informar sua raça, divergindo dos dados nacionais de 2017 em que 46,4\% consideram-se pardas ${ }^{4}$; esse fato pode ser atribuído à região em questão ser de descendência alemã, com população majoritariamente branca $(86,36 \%)$ conforme censo do IBGE de 2010.

Ao serem questionadas sobre o estado civil, a maioria era solteira, representando $70 \%$ das entrevistadas portadoras do vírus HIV e $100 \%$ das não portadoras, dados semelhantes aos encontrados em um estudo no Rio Grande do Norte em que a maioria das mulheres pertencia a esse estado civil ${ }^{2}$, dado esse que merece atenção visto ao risco de transmissão do vírus caso não sejam adotadas medidas preventivas. Quanto à escolaridade, $60 \%$ das entrevistadas HIV positivas possuíam o ensino fundamental incompleto, em consonância com os dados nacionais em que a maioria das gestantes possuem menos de 8 anos de ensino ${ }^{4}$. Nas gestantes HIV negativas, 3 afirmaram ter 0 ensino fundamental incompleto (25\%), 2, o ensino fundamental completo (16,67\%), 3, o ensino médio incompleto e 3, o ensino médio completo. A profissão mais citada no grupo HIV positivas foi agricultora (40\%), seguida de dona de casa (30\%), no outro grupo, foi safrista e desempregada com $33,33 \%$ cada uma.

Tabela 1. Perfil sociodemográfico das gestantes atendidas.

\begin{tabular}{|c|c|c|}
\hline Variáveis & HIV Positivas N (\%) & HIV Negativas N (\%) \\
\hline Idade média & 30 anos & 27 anos \\
\hline \multirow[t]{3}{*}{ Raça } & Branca $4(40,0)$ & Branca $8(66,7)$ \\
\hline & Negra $3(30,0)$ & Negra $1(8,3)$ \\
\hline & Parda $3(30,0)$ & Parda $3(25,0)$ \\
\hline \multirow[t]{6}{*}{ Escolaridade } & Ensino fundamental incompleto $6(60,0)$ & Ensino fundamental incompleto $3(25,0)$ \\
\hline & Ensino fundamental completo $2(20,0)$ & Ensino fundamental completo $2(16,7)$ \\
\hline & Ensino médio incompleto $0(0,0)$ & Ensino médio incompleto $3(25,0)$ \\
\hline & Ensino médio completo $0(0,0)$ & Ensino médio completo $3(25,0)$ \\
\hline & Ensino superior incompleto $1(10,0)$ & Ensino superior incompleto $1(8,3)$ \\
\hline & Ensino superior completo $1(10,0)$ & Ensino superior completo $0(0,0)$ \\
\hline \multirow[t]{6}{*}{ Profissão } & Agricultora $4(40,0)$ & Safrista $4(33,3)$ \\
\hline & Dona de casa $3(30,0)$ & Desempregada $4(33,3)$ \\
\hline & Professora $1(10,0)$ & Dona de casa $1(8,3)$ \\
\hline & Safrista $1(10,0)$ & Auxiliar de produção $1(8,3)$ \\
\hline & Desempregada $1(10,0)$ & Empresária $1(8,3)$ \\
\hline & & Doméstica $1(8,3)$ \\
\hline Estado Civil & Solteira $7(70,0)$ & Solteira $12(100,0)$ \\
\hline
\end{tabular}


Sobre o histórico sexual pregresso, a média de parceiros sexuais, durante a vida no grupo de HIV positivas, foi de 6,4 parceiros, sendo o máximo de 10 parceiros e o mínimo de 2 , porém 5 gestantes não quiseram/não souberam informar. No grupo HIV negativas, a média foi de 8,09 (máximo de 30 parceiros e mínimo de 2) e apenas uma entrevistada não soube/não quis informar. Quanto à média de parceiros no último ano, as gestantes HIV positivas tiveram 1,44 parceiros (máximo de 3 parceiros e mínimo de 1 parceiro), sendo que uma entrevistada não soube/não quis informar o número, e no grupo de HIV negativas, todas responderam à pergunta e a média foi de 1,08 parceiros (máximo de 2 parceiros e mínimo de 1 parceiro). Ao serem indagadas sobre o uso de preservativo, $40 \%$ das gestantes HIV positivas afirmaram sempre usar; já $58,33 \%$ das gestantes HIV negativas afirmaram fazer uso, às vezes, do preservativo, conforme explicitado na tabela 2. Esses dados reforçam a necessidade de maior educação em saúde, pois mesmo sabendo dos riscos de transmissão ainda assim é baixa a adesão ao uso de preservativo e nos dois grupos houve gestantes com mais de 1 parceiro no ano.

Tabela 2. Histórico sexual pregresso das gestantes atendidas.

\begin{tabular}{lrr}
\hline Histórico & HIV Positivas & HIV Negativas \\
\hline Média de parceiros sexuais na vida & 6,4 parceiros & 8,09 parceiros \\
Média de parceiros sexuais no último & 1,44 parceiros & 1,08 parceiros \\
ano & & Sempre 2 (16,67\%) \\
Uso de preservativo nas relações sexuais & Sempre $4(40 \%)$ & Às vezes $7(58,33 \%)$ \\
& Às vezes 3 (30\%) & Nunca 3 (25\%) \\
\hline
\end{tabular}

Em relação ao uso de medicações no grupo soropositivo, todas as gestantes faziam uso de terapia antirretroviral, fato atribuído a essas gestantes terem sido abordadas em um centro de referência em tratamento de HIV/Aids. No grupo soronegativo, $41,67 \%$ das gestantes afirmaram não fazer uso de medicamentos; das que fazem, o sulfato ferroso foi o fármaco mais citado (33,33\%), seguido de metildopa $(16,67 \%)$; deve ser considerado que essas gestantes também pertencem a um centro de referência de pré-natal de alto risco. Todas as gestantes responderam que não faziam uso de drogas ilícitas ou de álcool, exceto uma no grupo HIV positiva que não quis responder a essa pergunta, dados que divergem de outros estudos2. A respeito do uso de tabaco, 30\% das HIV positivas utilizam tabaco e $50 \%$ do outro grupo.

Quanto ao histórico obstétrico, o número médio de filhos e o número de gestações anteriores foram, respectivamente, de 1,9 (máximo 5 filhos e mínimo zero) e 2,4 gestações (máximo de 6 e mínimo de zero) no grupo soropositivo de 0,91 filhos (máximo de 3 e mínimo de zero) e 1,67 gestações (máximo de 3 e mínimo de zero) no outro grupo, dados semelhantes a outros estudos2. Não houve relato de natimortos em nenhum grupo. A média de abortos (espontâneos ou não) foi de 0,5 no grupo soropositivo e de 0,33 , no soronegativo, ambos os grupos tiveram o número máximo de 3 abortos e mínimo de zero. A idade gestacional média e o número de consultas prénatais foi, respectivamente, 23,3 semanas nas gestantes HIV positivas (máximo de 34 semanas gestacionais e mínimo de 3) e 3,4 consultas pré-natais (máximo de 6 e mínimo de zero) e, no outro grupo de gestantes, 28,25 semanas gestacionais (máximo de 39 e mínimo de 13) e 5,83 consultas (máximo de 10 e mínimo de 1). Duas gestantes HIV positivas não estavam com o número mínimo de consultas pré-natais preconizado pelo Ministério da Saúde (6 consultas), sendo que uma delas estava com 33 semanas gestacionais tendo realizado apenas

J. Health Biol Sci. 2019; 7 (1): 32-40
1 consulta. No outro grupo todas estavam de acordo com o número recomendado, o que pode estar relacionado ao fato de ser um pré-natal de alto risco. O tempo de diagnóstico do HIV foi de, no máximo, 48 meses e, mínimo, de 1 mês e 70\% descobriram ser portadoras do HIV durante o pré-natal dessa gestação ou de outra, corroborando os dados nacionais em que a maioria das mulheres são diagnosticas durante o pré-natal ${ }^{2,5}$.

\section{Planejamento materno e expectativas em relação ao futuro do bebê}

Ao serem questionadas sobre se estavam planejando ter filhos, $60 \%$ das gestantes soropositivas estavam e $50 \%$ das soronegativas. Quando solicitadas para definir em uma palavra a sua gravidez, a palavra mais citada no grupo HIV positivo foi "amor" (33,33\%), outras foram "salvação", "realização", "alegria, muita alegria", "felicidade", "um acaso, um acidente" e "surpresa". No outro grupo, a palavra mais dita foi "felicidade" (30\%), outras mencionadas foram "tranquilidade", "novidade", "ser mãe", "não sei", "bênção", "realização", "expectativa” e "tudo".

Quando indagadas sobre as expectativas do futuro do bebê, em ambos os grupos, as futuras mães esperavam que seus filhos viessem com saúde, sendo, no grupo soropositivo, essa esperança muito ligada a não ter o vírus HIV e a possibilidade de um futuro melhor para essas crianças, com melhores oportunidades que suas mães

“...que venha livre do HIV, que a gente possa fazer de tudo para que a saúde da criança seja perfeita, né!"

"Que tenha muita saúde, querendo ou não a gente fica preocupada, né, porque de muitas crianças, algumas acontece e nasce soropositiva, né! Então eu quero que ela tenha muita saúde, isso aí!", 
"Não sei, acho que se ele não tiver HIV, acho que vai se muito bom."

Também houve concordância de que o futuro seja melhor para essas crianças, que elas tenham melhores oportunidades que suas mães.

“Eu espero que... dá um bom futuro para ele, né, o qual eu não tive."

"Que tenha várias oportunidades, né? Ahmm... assim, tipo que, eu não tive essas oportunidades, que ele consiga um emprego melhor, um salário melhor também, né?"

"Que tenha um futuro melhor, não tenha tanta violência, assalto como tem no mundo."

Houve concordância em relação aos anseios maternos das gestantes soropositivas e soronegativas, tendo em vista que todas as gestantes, soropositivas e soronegativas almejam um bebê saudável como objetivo principal antes, durante e após a concepção, juntamente com a representação de uma prova do bom funcionamento do corpo e da mente. Esses resultados apresentam consonância com a literatura, como em Carvalho e Piccinini $(2006)^{6}$.

Assim, fica evidenciado que as expectativas em relação à gestação e ao bebê por mulheres soropositivas não estão vinculadas ao interesse de interromper a gestação, mas sim, apenas ao desejo que seus filhos nasçam com saúde e que não recebam delas o vírus11. 0 medo da transmissão vertical pode ser justificado pelo fato de a Aids ser uma doença sem cura, levando as gestantes à crença da morte intraútero, somado ao receio da transmissão vertical considerando um erro pessoal serem soropositivas ${ }^{6,13,14}$ e esperam que seus filhos não cometam o mesmo erro que elas

"Ah, um futuro bem mais melhor... Que sabe viver a vida, não se estragar como eu me estraguei".

$\mathrm{Na}$ maioria dos casos de gestantes soropositivas, ter um filho saudável seria uma motivação para prosseguirem com o tratamento ${ }^{14}$, e o fato de o seu bebê nascer soronegativo a isentaria do sentimento de culpa que elas, eventualmente, podem carregar $^{11}$. Além disso, mesmo com a possibilidade de transmissão, o fato de estar gerando um filho cria um sentimento de estarem valorizando a si próprias, uma vez que, mesmo que, na presença do HIV, o filho simboliza a vida e desvincula a infecção pelo HIV com o diagnóstico de fim da vida. Então, a possível vivência da maternidade gera um processo de ressignificação na vida das gestantes, podendo auxiliar no fortalecimento do enfrentamento do diagnóstico de HIV e da TARV ${ }^{10}$. Com isso, fica evidenciado que, para melhorar as expectativas de tais gestantes, o aconselhamento deve sempre se fazer presente, tanto do fato de serem soropositivas, terem diagnóstico recente, quanto do risco de transmissão vertical da doença. De qualquer forma, tanto a satisfação como o medo são experiências comuns nas gestantes no geral, o que indica semelhança entre os dois grupos.

\section{Temores relacionados à gestação e ao trabalho de parto}

Quando interrogadas sobre se elas sentem medo da gestação ou do trabalho de parto e o porquê, a maioria respondeu que tem medo, independente do grupo, assim como em Tostes e Seidl $(2016)^{15}$. No grupo soronegativo, houve gestantes que relataram não terem medo, pois elas já passaram por uma gestação e sabem como é. Entre as soronegativas que apresentam medo, o motivo mais prevalente que as gestantes apresentam está muito relacionado à dor na hora do parto e à nuliparidade, ou seja, medo do desconhecido.

“...pela dor, por tudo que falam assim sabe?"

"...de sentir dor, disso não tenho medo, tenho medo assim, referente a vida do bebê, o que possa vir."

"...é uma novidade para mim, tudo novo, né? Muita novidade!".

No grupo soropositivo, alguns sentimentos, assim como em estudos anteriores, foram descritos por várias dessas gestantes soropositivas, como medo e culpa de um diagnóstico positivo do recém-nascido, medo da própria morte, impossibilidade de amamentar, medo em relação ao momento do parto, entre tantas outras dúvidas acerca de sua situação $0^{6,11,16}$. Esses temores, entretanto, não foram compartilhados por todas as mulheres desse grupo, houve pacientes, por exemplo, que relataram não possuir medo por já terem vivido a experiência de gestar e/ou porque acreditam estar bem assistidas pelos médicos fator essencial para as gestantes soropositivas mostrarem-se conformadas com a via de parto sugerida pelo médico que, normalmente, é o parto cesáreo devido ao menor risco de transmissão do vírus ao feto ${ }^{15,16}$. As demais que responderam que têm medo, semelhante às soronegativas, citam a dor ou ainda o medo de passar o vírus para o bebê

\footnotetext{
"Um pouco, porque dizem que o parto normal é muito dolorido, sabe?"

"Só da cesariana porque diz que os dois dias próximos são muito doloridos."

"Depois que eu descobri o HIV sim, porque eu fiquei com medo de passar para o bebê"

"Tenho medo de que chegue a hora e eu tenha um parto muito espontâneo, muito rápido e não tenha tempo de fazê o AZT"

"Por causa do vírus, né?".
}

Observou-se, então, uma divergência entre os principais temores das gestantes. No grupo soropositivo, prevaleceu o medo da transmissão vertical e da administração de AZT durante o parto como as principais preocupações; já no grupo soronegativo, a dor do parto foi a mais citada. Portanto, fica evidenciado que o período gestacional é um momento crítico emocional para as mulheres, independente se há, ou não, a infecção pelo vírus do HIV ${ }^{14}$, pois há, em ambos os grupos gestantes que convivem com algum medo ou receio em relação à gestação, à exceção 
das pacientes multíparas que, aparentemente, neste estudo demonstraram estar mais confortáveis com a gestação e o parto devido a não considerarem uma experiência nova. No caso das mães soropositivas, entretanto, a presença do medo e da culpa associa-se a todo processo já existente, pois temem que seus filhos nasçam doentes ou até mesmo morram, o que torna uma situação muito mais crítica emocionalmente para essas mulheres, mostrando que como em outros estudos, existe uma sobrecarga emocional nesse grupo ${ }^{16,17}$.

\section{Percepção de saúde}

Ao serem questionadas em relação à saúde e à autopercepção sobre estarem saudáveis e o porquê da resposta, três gestantes, no grupo soronegativo, afirmaram não se sentir saudáveis devido à má alimentação, presença de diabetes gestacional e o uso de drogas (tabaco)

\section{"Não porque eu sou gorda demais, obesa!" \\ "...nem tanto por causa do diabetes, mas antes eu me considerava. Tá, eu fumava, mas mesmo assim né!" \\ "porque eu como muita porcaria, né! Chocolate e bolacha, salgadinho, mas agora eu até parei, né! Por causa da gestação"}

As demais, desse mesmo grupo, consideram-se saudáveis pela boa alimentação, atividade física, por não fazer uso de medicamentos ou drogas lícitas/ilícitas

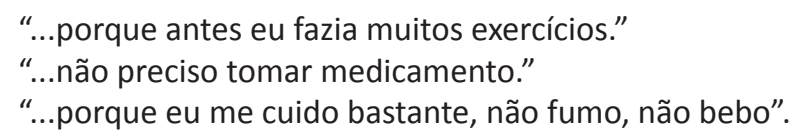

No grupo HIV positivo, todas se consideram saudáveis por fazerem o tratamento para o HIV de forma regular e correta, pois desejam que seus filhos sejam saudáveis, sem o vírus, e que elas possam criá-los e educá-los ${ }^{11}$, sendo esse o principal motivo para a manutenção e para a realização correta do tratamento, uma vez que necessitarão estar saudáveis para realizar os cuidados necessários relacionados à maternidade, passando a perceber o filho como extensão de si próprias ${ }^{14}$. Outro aspecto citado pelas mães HIV positivas foi em relação à mudança de estilo de vida para melhor

“...porque em vista do que eu era antes, hoje eu sou saudável, antes eu não tinha saúde, nem mental, nem psicológica, nada."

“...mesmo com o vírus sim, porque eu tô me sentindo bem, tô fazendo tratamento certinho, né!"

“...não tenho gordura no sangue, não tenho nada, só sou

soropositiva, mas tá indetectável, minha imunidade é boa."

"...acho que HIV é uma doença como outra qualquer, se tu

te cuidar, se tu usar teu medicamento normalmente tu vai

viver 10, 20, 30, 40 anos."

“...porque eu faço uso do medicamento bem, de forma bem

correta, né? Me cuido, não uso drogas, não uso álcool...".

Mostrando, novamente, que a gestação e a futura maternidade podem gerar um processo de ressignificação na vida dessas gestantes, podendo auxiliar no fortalecimento do enfrentamento do diagnóstico de HIV e da TARV ${ }^{10}$.

\section{Conhecimento sobre transmissão vertical}

A transmissão vertical é a que se dá através da passagem do vírus do HIV da mãe para o bebê, podendo ocorrer através da placenta (durante a gestação), no momento do trabalho de parto e no aleitamento materno. O conhecimento da doença por seus portadores, ou de pessoas envolvidas com a questão está diretamente relacionada com o fortalecimento de medidas de prevenção da doença ${ }^{18}$.

Em um estudo sobre o conhecimento das gestantes acerca da transmissão vertical, realizado no Brasil, que entrevistou 120 gestantes, mostrou que apenas $76,7 \%$ das gestantes entrevistadas concordavam que o vírus do HIV poderia ser transmitido ao bebê durante a gestação; 58,3\% concordavam que o vírus poderia ser transmitido durante o parto e apenas $50 \%$ concordavam que o vírus poderia ser transmitido através da amamentação, as demais, ou discordavam, ou não sabiam ${ }^{17}$.

Dessa forma, as gestantes foram questionadas sobre quais as formas de contaminação do HIV da mãe para o bebê para analisar o conhecimento dessas parturientes sobre a doença. No grupo soropositivo, elas possuíam melhor conhecimento sobre as formas de contaminação, porém nenhuma soube responder corretamente
“Amamentação. Não pode amamentar, né? Que eu sei é isso."
"É se não tomá o medicamento, né?"
"Diz que criança não pode mamar, né? Isso que é uma judiaria, é meu sonho..."
"No momento do parto, acredito que... leite materno"
"No parto, não usando o medicamento, só esses dois"

Assim, observou-se uma prevalência na menção de certa forma correta sobre a transmissibilidade pela amamentação. A impossibilidade de amamentação, entretanto, traz à tona um sentimento de maior sofrimento e tristeza desse grupo em relação à maioria das mães soronegativas. No grupo soronegativo, 66,67\% das gestantes não souberam responder; as que responderam, também fizeram afirmações incompletas
"É... amamentação, na hora do parto."
"Acho que desde a concepção, né?"
"Na hora do parto e na hora do leite"
"Pelo parto normal" 
Como o aleitamento é preconizado pelo Ministério da Saúde, por formação de laços afetivos e melhora do sistema imunológico do bebê pelos benefícios dos compostos do leite materno ${ }^{19}$, é de extrema importância que as gestantes sejam muito bem orientadas com suporte psicológico para essa frustração ${ }^{13,20}$. Muitas parturientes têm o imaginário que todas as mães deveriam amamentar, então, nesse grupo, pode ocorrer a ideia de que a não amamentação acarrete um afastamento entre mãe e filho e receiam que isso não possa ser revertido futuramente, o que faz sobrepor - por vezes - o risco de transmissão para o filho pelo desejo de amamentar ${ }^{15}$. Evidenciando isso, fica claro que a não amamentação é mais um desafio para as gestantes com HIV, uma vez que, para todas elas, é vista como um ato de afeto e carinho, e a partir do momento em que não podem dar para seus filhos acaba gerando sofrimento, o que não pode ser negligenciado pela equipe de saúde que a atende ${ }^{17,21}$. Futuramente, entretanto, esse pode não ser mais um entrave para mães soropositivas que preencham três critérios: carga viral estável com menos de 50 cópias durante a gravidez e a amamentação (1), estar fazendo uso de terapia antirretroviral combinada (2) e estar em acompanhamento médico regular $(3)^{22,23}$. Estudos recentes demonstram tendência de que seja aberta a possibilidade às mães soropositivas de optarem, ou não, por amamentar pelo menos até 1 ano de idade, expondo os riscos e os benefícios para uma decisão compartilhada ${ }^{22,23}$, ao contrário do prezado pelas Diretrizes brasileiras de 2018 que mantiveram a contraindicação absoluta do aleitamento materno ${ }^{6}$. Ainda não é indicada a recomendação ativa do aleitamento materno para essa população. Existem evidências de que a exposição prolongada de recém-nascidos em aleitamento materno exclusivo por mães soropositivas com carga viral detectável em tratamento com terapia antirretroviral combinada favoreça a infecção, não podendo descartar falha no seguimento do tratamento da paciente, pois $67 \%$ dos casos de infecção acontecem após 6 meses de amamentação e mais de $30 \%$ em 1 ano. Há uma forte sugestão, contudo, que a transmissão em pacientes com carga viral indetectável seja virtualmente de $0 \%{ }^{23}$, sendo possível que, mediante o surgimento de estudo maiores que confirmem essas hipóteses, mulheres com carga viral indetectável e em tratamento com terapia antirretroviral combinada tenham recomendação de amamentar 22,23 .

Outro fator decisivo para a transmissão vertical do HIV é o fornecimento do diagnóstico sem suporte psicológico e técnico para as gestantes, em que predomina o medo quanto ao surgimento da gestação, não sendo somente um temor pelo risco de infecção, mas também o temor social que o HIV positivo carrega associado a uma gestação ${ }^{24}$. Somado à falta de suporte, o preconceito é outro aspecto que influencia negativamente o compartilhamento de informações relacionadas à transmissão. Ele é citado por todas as gestantes, que, em algum momento, sofreram situações de discriminação, o que dificulta o enfrentamento da doença, muitas vezes, culminando em pouco acolhimento e transmissão de informações deficitárias no prénatal. Visto que o preconceito parte desde as ações em saúde destinadas a portadores da doença, quando nem sempre o desejo de gestar é considerado, como se esse não existisse, e a maternidade nem devesse ser cogitada pelas portadoras do $\mathrm{HIV}^{24}$.

Assim, a sexualidade deve fazer parte da assistência prestada à mulher soropositiva e seu parceiro. Desejos, direitos e anseios sexuais e reprodutivos são assuntos cruciais no atendimento integral do binômio homem-mulher, de forma que se devem incluir, na consulta, temas como a vontade de gestar, as formas de transmissão durante o ato sexual e as condições que permitam a concepção de forma segura e saudável. Cabe aos profissionais de saúde trazer tais assuntos à tona entre seus pares, dissociando, dessa forma, o título de tabu da existência de uma criança concebida a partir de uma portadora de HIV².

Um dos principais fatores para a redução da transmissão vertical é conseguir que as gestantes ao pré-natal venham a aderir o quanto antes e dar início ao tratamento antirretroviral na idade gestacional adequada para que a transmissão vertical seja evitada ${ }^{18,21,26}$. Portanto, a conscientização na gestação é fundamental para que as taxas de infecção vertical diminuam, visando à adesão ao tratamento. Muitas gestantes não aderem ao tratamento devido aos efeitos colaterais dos medicamentos; portanto, a presença de apoio de uma equipe de saúde é fundamental para a adesão ao tratamento ${ }^{21}$.

A transmissão vertical do vírus HIV, portanto, é decorrente da falta de cuidados das gestantes no período da gestação e do puerpério e o conhecimento sobre as formas de transmissão poderia acarretar menor incidência de recém-nascido contaminado $^{18}$. Tal fenômeno pode ser observado antes da concepção no comportamento sexual de risco, negligenciando a possibilidade de infecção pelo desejo de gestar, pelas relações de confiança com seus parceiros ou pela falta de conhecimento da transmissibilidade do HIV, em que muitas mulheres acham que adquirir o vírus nunca acontecerá com elas ${ }^{27}$. Portanto, um pré-natal de qualidade, com o tratamento antirretroviral combinado é de fundamental importância para reduzir as taxas de transmissão vertical ${ }^{18,27}$.

\section{Teste anti-HIV e mudanças de perspectivas}

Atualmente, uma série de diagnósticos de HIV na população feminina ocorre no momento da gestação. Isso acontece porque a testagem para o HIV é uma das medidas disponíveis para a prevenção da transmissão vertical do vírus e é ofertado para todas as gestantes com ou sem pré-natal26. A não realização do teste implica uma perda de oportunidade única de intervenção na gestante infectada para evitar a transmissão vertical ${ }^{27}$.

O momento da testagem ocorre com diversos aspectos psicológicos envolvidos, devendo ocorrer por partes dos profissionais da saúde uma série de aconselhamentos pré e pós teste18,26. Esse é um fator importante porque o diagnóstico do HIV/Aids é envolvido de diversas questões emocionais, como sentimento de culpa, medo, sofrimento. O Ministério da Saúde preconiza que os profissionais da Saúde no momento 
da testagem e, principalmente, se positivo, ofereçam apoio emocional e orientações que ajudem a amenizar a ansiedade e esclarecer as dúvidas ${ }^{21}$. Deve- se esclarecer quanto às opções de tratamento, dirimir as dúvidas quanto às formas de transmissão do vírus do HIV da mãe para o bebê e a diferença de HIV e Aids ${ }^{26}$.

Sabendo desse fato, o estudou buscou perguntar se as parturientes haviam realizado o teste anti-HIV no pré-natal atual; se não haviam, foram questionadas sobre suas expectativas em relação à gestação e ao bebê, se afirmativo, se suas expectativas mudaram após o resultado. No grupo HIV negativo, apenas uma gestante não havia realizado o teste e suas expectativas foram

"que venha bem, e depois que continue com saúde que nem os outros".

As que responderam que realizaram o teste, disseram que suas expectativas não mudaram, principalmente, pela certeza de que o teste daria negativo

“Não porque eu já tinha certeza que eu não tinha, porque

não tinha como..."

"porque era o esperado"

"porque meu marido já tinha feito antes"

Ainda no grupo que realizou o teste e as participantes são soronegativas, algumas referiram receio de que, se o teste tivesse dado positivo, suas expectativas poderiam ser diferentes

"Mas acho que teria sim se fosse positivo"

"eu não saberia lidar, né? ... porque é muita carga, muito peso pra gente, né? Saber que eu tô vivendo com essa doença"

No grupo soropositivo, três gestantes não realizaram o teste anti-HIV no pré-natal atual porque já tinham o diagnóstico da soropositividade e, em relação às expectativas delas sobre a gestação e o bebê relataram aumento no desejo de cuidado e, mais uma vez mencionado, o temor da transmissão vertical:

"as melhores possíveis, vou cuidar muito"

"eu já tive uma gravidez e meu filho não teve porque eu me cuidei, porque eu tomei os remédios, porque eu fiz tudo correto"

Entre as que realizaram o teste, 50\% responderam que as expectativas não mudaram porque estão tomando a mediação correta

\footnotetext{
“porque eu consultei com a doutora e com a psicóloga, Elas disseram para eu ficar tranquila né, que se eu fizesse o tratamento certinho ia dar tudo certo" "usando sempre os medicamentos certinho, né, a gente pode ir levando uma vida normal"

"Não mudou, só fiquei com um pouquinho de medo do bebê".
}

A outra metade respondeu que suas expectativas mudaram, e afirmaram

\footnotetext{
"Mudaram, é que a gente se sente um pouco abalado" "a gente fica meio que sem tê o que explica, sei lá, a gente fica meio que embaraçado".
}

Dessa forma, muitas gestantes que se deparam com a testagem do HIV, em um momento inicial se chocam com diferentes situações emocionais, fato evidenciado no grupo que não recebeu diagnóstico, quais seriam as possíveis reações, sendo que muitas relataram que seriam um peso muito grande para carregar, com o qual não saberiam lidar. 0 grupo que recebeu diagnóstico evidenciou que tal sentimento, de fase inicial, que é de angustia, culpa, se transforma em um sentimento que, com as condutas realizadas corretamente, como o tratamento, torna-se superável24. É perceptível, nos relatos, também que o acesso ao atendimento interdisciplinar, realizado por médicos e psicólogos foi capaz de tranquilizar as futuras mães quanto ao diagnóstico da doença, gerando um sentimento de aceitação. Portanto, o acompanhamento multidisciplinar é essencial para abordar tais gestantes no âmbito psicossocial que estão vivendo no momento18,24.

\section{CONCLUSÃO}

Diante do exposto, fica evidente que sentimentos variando de felicidade até medo são comuns em ambos os grupos de gestantes de alto risco pois, além de ser uma fase de mudança física, psicológica e social, estão convivendo com comorbidades além do esperado. Adicionalmente, a partir desses relatos, é perceptível que a infecção pelo HIV pode repercutir de variadas formas na percepção das gestantes em relação à gestação. Enquanto as mães soropositivas para HIV já diagnosticadas previamente veem a gestação como um motivo de superação e materialização de um tratamento feito corretamente com pragmatismo, as mães recém-diagnosticadas no pré-natal podem se sentir culpadas, abaladas e sem estrutura emocional para levar a gestação adiante.

Visto isso, o suporte educacional e psicológico sobre a transmissão do HIV durante a gestação - mais uma vez torna-se indispensável quando se almeja uma boa percepção da gestação por gestantes soropositivas e redução nas taxas de crianças menores de 13 anos infectadas por transmissão vertical, além de ser uma ferramenta de educação em saúde em ambos os grupos.

A impossibilidade de aleitamento gera sentimentos no grupo soropositivo que merecem atenção psicológica. Intervenções nos grupos tanto dirigidas ao fornecimento de informações quanto ao desconhecimento sobre transmissão vertical é alto em ambos os grupos, como também troca de experiência e sentimentos são importantes.

Muitas vezes, a grávida de risco passa apenas por uma especialidade médica, sendo a única preocupação que a 
criança nasça com saúde; entretanto, fica evidenciado que deve existir uma atenção multidisciplinar, para que educação em saúde dessas gestantes se inicie já no pré-natal, com o teste anti-HIV, ou orientação para as já diagnosticadas sobre a forma adequada de tratamento antirretroviral pré-natal, a via de parto, o tratamento do recém-nascido até 6 meses de idade e o esclarecimento sobre a contraindicação do aleitamento materno.

\section{REFERÊNCIAS}

1. Scherer LM, Borenstein MS, Padilha MI. Gestantes/puérperas com HIV/Aids: conhecendo os déficits e os fatores que contribuem no engajamento para o autocuidado. Esc Anna Nery Rev Enferm. 2009; 3(2): 359-65. doi: http://dx.doi. org/10.1590/S1414-81452009000200017.

2. Lima SKSS, Sousa KKB, Dantas SLC, Rodrigues ARM, Rodrigues IR. Caracterização das gestantes com HIV/Aids admitidas em hospital de referência. SANARE. 2017 Jan-Jun; 16(1): 45-51.

3. Porto TSR, Silva CM, Vargens OM. Female healthcare professionals' behaviour and attitudes in the context of the feminisation of HIV/Aids: gender vulnerability analysis, AIDS Care.2017; 29(1): 49-55.

4. Ministério da Saúde [BR]. Secretaria de Vigilância em Saúde. Departamento de DST, Aids e Hepatites Virais. Boletim Epidemiológico - Aids e DST. Brasília: Ministério da Saúde; 2017 [acesso 2018 Out 23]. Disponível em: http://www. aids.gov.br/pt-br/pub/2017/boletim-epidemiologico-HIV/Aids-2017.

5. Silva CM, Alves RS, Santos TS, Bragagnollo GR, Tavares CM, Santos AAP. Panorama epidemiológico do HIV/Aids em gestantes de um estado do Nordeste brasileiro. Rev. Bras. Enferm. 2018; 71(Supl. 1): 568-576.

6. Carvalho FT, Piccinini CA. (2006). Maternidade em situação de infecção pelo HIV/Aids: um estudo sobre os sentimentos de gestantes. Rev. Inter Psicol. 2006 Jul-Dez; 10(2): 345-355. doi: http://dx.doi.org/10.5380/psi.v10i2.7693.

7. Lima SS, Silva LCS, Santos MV, Martins JP, Oliveira MC, Brasileiro ME. HIV in pregnancy: prenatal, labor and puerperium. Ciência\&Saúde. 2017; 10(1): 56-61.

8. Brito AM, Sousa JL, Luna CF, Dourado I. Tendência da transmissão vertical de Aids após terapia anti-retroviral no Brasil. Rev. Saude Publica. 2006; 40(Suppl): 18-22.

9. Ministério da Saúde [BR]. Secretaria da Vigilância em Saúde. Departamento de Vigilância. Protocolo Clínico e Diretrizes Terapêuticas para Prevenção da Transmissão Vertical do HIV, Sífilis e Hepatites Virais, Brasília: Ministério da Saúde; 2018.

10. Levandowski DC, Canavarro MC, Pereira MD, Maia GN, Schuck LM, Sanches IR. Maternidade e HIV: revisão da literatura brasileira (2000-2014). Arq. bras. psicol. 2017; 69 (2): 34-5, 2017.

11. Moura E, Praça N. Transmissão vertical do HIV: expectativas e ações da gestante soropositiva. Rev. Latino-Am Enfermagem. 2006; 14(3): 405-413. doi: http://dx.doi.org/10.1590/S0104-11692006000300015.

12- Bardin L. Análise de Conteúdo. São Paulo: Edições 70; 2011.

13. Faria ER, Piccinini CA. Motherhood in the context of HIV/Aids: pregnancy and the baby at three months. Estud. Psicol. (Campinas). 2010 Apr-Jun; 27(2): 147-159. doi: http://dx.doi.org/10.1590/S0103-166X2010000200002.

14. Rubiano Mesa YL, Munevar Torres RY, Sánchez BG. Más allá de mí: cuidarme para proteger mi hijo. Experiencias de mujeres gestantes con VIH/SIDA. Rev Univ Ind Santander Salud. 2016; 48(3): 353-363. doi: http://dx.doi.org/10.18273/ revsal.v48n3-2016009.

15. Tostes NA, Seidl EMF. Expectativas de gestantes sobre o parto e suas percepções acerca da preparação para o parto. Temas psicol. 2016 Jun; 24(2): 681-693. doi: http://dx.doi.org/10.9788/TP2016.2-15.

16. Rigoni E, Pereira EOS, Carvalho FT, Piccinini CA. Sentimentos de mães portadoras de HIV/Aids em relação ao tratamento preventivo do bebê. Psico-USF. 2008; 13(1): 75-83. doi: http://dx.doi.org/10.1590/S141382712008000100010.

17. Jordão BA, Espolador GM, Sabino AMNF, Tavares BB. Conhecimento da gestante sobre o HIV e a transmissão vertical em São José do Rio Preto, São Paulo, Brasil. Rev. Bras. Pesq. Saúde. 2016 Abr-Jun; 18(2): 26-34.

18. Leal AF, Roese A, Sousa AS. Medidas de prevención de la transmisión vertical del VIH empleadas por madres de niños seropositivos. Invest Educ Enferm. 2012; 30(1): 44-54.

19. Toma TS, Rea MF. Benefícios da amamentação para a saúde da mulher e da criança: um ensaio sobre as evidências. Cad. Saúde Pública. 2008; 24(Suppl 2): 235-246. doi: http://dx.doi.org/10.1590/S0102-311X2008001400009.

20. Bazani AC, Silva PM, Rissi MRR. A vivência da maternidade para uma mulher soropositiva para o HIV : um estudo de caso. Sal \& Transf. Soc. 2011; 2(3): 45-55.

21. Lemos LMD, Gurgel RQ, Fabbro ALD. Prevalência da infecção por HIV em parturientes de maternidades vinculadas ao SUS. Rev Brasil Ginecol Obstetr. 2005; 27(1): 32-6. doi: http://dx.doi.org/10.1590/S0100-72032005000100007.

22. Flynn PM, Taha TE, Cababasay M, Fowler MG, Mofenson LM, Owor M. Prevention of HIV-1 Transmission Through Breastfeeding. J Acquir Immune Defic Syndr. 2018 Apr; 77(4), 383-392. doi: 10.1097/QAI.0000000000001612.

23. Kahlert CR, Aebi-Popp K, Bernasconi E, Martinez de Tejada B, Nadal D, Paioni $\mathrm{P}$, et al. Is breastfeeding an equipoise option in effectively treated HIVinfected mothers in a high-income setting? SMW Swiss Med Wkly. 2018 Jul; 148: w14648. doi: 10.4414/smw.2018.14648.

24. Moura EL, Kimura AF, Praça NS. Ser gestante soropositivo para o Vírus da Imunodeficiência Humana: Uma leitura àluz do Interacionismo Simbólico. Acta paul. enferm. 2010 Mar-Abr; 23(2): 206-211, 2010. doi: http://dx.doi. org/10.1590/S0103-21002010000200009.

25. Cordova FP, Luz AM, Innocente AP, Silva EF. HIV seropositive women and their partners facing the decision of a pregnancy. Rev Bras Enferm. 2013 JanFev; 66(1): 97-102. PubMed PMID: 23681386.

26. Ministério da Saúde [BR]. Programa Nacional de DST e Aids. Recomendações para Profilaxia da Transmissão Vertical do HIV e Terapia Antirretroviral em Gestantes. Brasília: Ministério da Saúde; 2010.

27. Souza PRB Júnior, Szwarcwald CL, Aristides B Júnior, Carvalho MF, Castilho EA. Infecção pelo HIV durante a gestação: Estudo-Sentinela Parturiente, Brasil, 2002. Rev. Saúde Públ. 2004; 38(6):764-72. doi: http://dx.doi.org/10.1590/ S0034-89102004000600003.

\section{Como citar este artigo/How to cite this article:}

Hernandes CP, RochaRK, Hausmann A, Appelt JB, Marques CM. Análise qualitativa dos sentimentos e conhecimentos acerca da gestação e do HIV em gestantes soropositivas e soronegativas. J Health Biol Sci. 2019 Jan-Mar; 7(1):32-40. 